\title{
Musculoskeletal Disorder Costs and Medical Claim Filing in the US Retail Trade Sector
}

\author{
Anasua BHATTACHARYA ${ }^{1 *}$ and J. Paul LEIGH ${ }^{2}$ \\ ${ }^{1}$ Risk Evaluation Branch, Education and Information Division, National Institute for Occupational Safety and \\ Health, Centers for Disease Control and Prevention, 4676 Columbia Parkway MS C-15, Cincinnati, OH \\ 45226, USA \\ ${ }^{2}$ Center for Healthcare Policy and Research and Department of Public Health Sciences, University of \\ California, Davis, One Shields Avenue, Davis, CA 95616, USA
}

Received February 25, 2010 and accepted November 19, 2010 Published online in J-STAGE June 21, 2011

\begin{abstract}
The average costs of Musculoskeletal Disorder (MSD) and odds ratios for filing medical claims related to MSD were examined. The medical claims were identified by ICD 9 codes for four US Census regions within retail trade. Large private firms' medical claims data from Thomson Reuters Inc. MarketScan databases for the years 2003 through 2006 were used. Average costs were highest for claims related to lumbar region (ICD 9 Code: 724.02) and number of claims were largest for low back syndrome (ICD 9 Code: 724.2). Whereas the odds of filing an MSD claim did not vary greatly over time, average costs declined over time. The odds of filing claims rose with age and were higher for females and southerners than men and non-southerners. Total estimated national medical costs for MSDs within retail trade were \$389 million (2007 USD).
\end{abstract}

Key words: Low back syndrome, Lumbar region, MarketScan

Musculoskeletal disorders (MSDs) refer to conditions that involve nerves, tendons, muscles, joints, cartilage, and spinal discs ${ }^{1)}$. MSDs include sprains, strains, tears, back pain, tendonitis, carpal tunnel syndrome (CTS), and hernia among others. From 1992 to 2007, MSDs accounted for roughly 29-34\% of all occupational injuries and illnesses involving days away from work ${ }^{1,2)}$. The retail trade sector generates more MSDs than most other sectors including construction, wholesale trade, transportation and public utilities. Retail trade includes a variety of businesses such as hardware stores, gas stations, car dealerships, clothing stores, restaurants, drug stores, liquor stores, and florists.

MSDs generate higher medical and lost productivity costs than typical occupational injuries ${ }^{3)}$. On average, the median number of days away from work for MSDs were $22 \%$ higher than other Bureau of Labor Statistics (BLS) injuries; the median for carpal tunnel syndrome

*To whom correspondence should be addressed.

E-mail: ABhattacharya1@cdc.gov was twice as high as for other BLS injuries ${ }^{1,2)}$. The burden of MSDs is not equally shared across the population. The recovery time for musculoskeletal injuries increases significantly with age ${ }^{4)}$. Peele et al. (2005) ${ }^{5)}$ find that older workers incur significantly more lost work days and higher wage replacement (workers compensation) payments compared to younger workers with similar musculoskeletal injuries. Females experience a higher disproportionate share of MSDs than males ${ }^{1)}$. Whereas we are not familiar with studies on variation in numbers or costs of MSDs across regions of the US, it is plausible that such variation exists given well-documented variation in the mix of industries, workers compensation systems, and medical costs for job-related and non-job-related diseases across regions ${ }^{6,7)}$. Finally, the high prevalence and significant costs of MSDs generate attention from policy makers and have led to proposed ergonomic standards ${ }^{8)}$.

Despite the significance of the problem, we are not aware of studies that specifically address medical costs of MSDs in retail trade. This study examined utiliza- 
tion of medical services to treat for MSD-related medical claims using Thomson Reuters MarketScan databases. The medical claims included both occupational and non-occupational claims. We believe data that included non-occupational claims was appropriate, perhaps even superior, for two reasons. First, workers compensation medical prices are alleged to be inflated ${ }^{9}$. Second, studies suggest that more than half of job-related MSDs are not reported to workers compensation ${ }^{10)}$.

The Thomson Reuters MarketScan data warehouse is a family of databases containing individual level healthcare claims, lab test results, and hospital discharge information from large employers, managed care organizations, hospitals, Medicare, and Medicaid. These databases are based on a large convenience sample. We used the MarketScan database on medical claims data from about 45 large private firms. These databases are proprietary to Thomson Reuters Inc. The MarketScan databases include comprehensive information on medical services utilization and cost for a large population of workers and their families ${ }^{11)}$. The data released by MarketScan externally to clients has been certified as de-identified according to the Health Insurance Portability and Accountability Act rules therefore, do not require following Institutional Review Board standards. The precise number of retail firms among these 45 is unknown to us, but our sample sizes ( $n=102,023$ employees with MSD claims) are large.

This study utilized the medical costs of MSDs in retail trade that included inpatient admissions and outpatient services. We defined retail trade by North American Industry Classification System codes 44 and 45 which comprised establishments engaged in retailing merchandise, generally without transformation, and rendering services incidental to the sale of merchandise. The MSD costs and odds of filing claims were compared across gender, age groups, International Classification of Disease Codes - 9 (ICD-9 codes) and four Census regions for years 2003-2006. The ICD-9 codes are identified in Table 2. The four regions were Northeast, South, Midwest, and West. Costs were expressed in constant, 2006, US dollars.

All employees in retail trade who had any claims were included. The sample consisted of 973,947 employees ages 18-64; of these employees, 773,899 (79.5\%) had at least one medical claim over the four years without any double counting and comprised our beginning sample. Roughly thirteen percent $(n=102,023)$ of these 773,899 employees had claims that were MSDrelated and $3.5 \%$ of all claims were MSD related.

Our statistical method used $t$-tests and $\chi^{2}$ to test for differences in numbers and dollar amounts of claims across groups as well as grouped multiple logistic regressions to test for differences in filing claims. Four dependent variables for the logistic regressions included likelihood of filing: any MSD claim; only MSD claim with lumbar region; and only MSD claims with and without low back syndrome. The latter three were selected because they were the most expensive and most frequent of all MSDs studied here. The percents out of all claims for each of these dependent variables were: $3.5 \%$ for all MSD claims; $0.12 \%$ for lumber stenosis; $1.52 \%$ for low back; and $2 \%$ for non-low back. Because these percents were less than $10 \%$, odds ratios did not require any adjustments ${ }^{12)}$.

The distribution of employees and costs for all years combined related to MSDs are presented in Table 1. Numbers of total employees with any claims, numbers of employees with only MSD claims, and average costs of MSD claims per employee appear across the top of the table.

Women reporting at least one claim numbered 494,306 whereas men numbered 279,593 $(p<0.0001)$ (Table 1). Women's percentage of MSD claims $(69.45 \%)$ was higher than men $(30.55 \%)(p<0.0001)$. This contrasts with national employment in retail trade in which male employees were more numerous ${ }^{13}$. The distribution of MSDs across age groups was not equal $(p<0.0001)$. The highest age group percentage with MSDs was 45 through $54(27.45 \%)$ and this compared to $22.00 \%$ for the "all claims" category. Average costs increased with age. The distribution for MSDs across regions was not equal $(p<0.0001)$. The highest region percentage for MSDs was South $(60.02 \%)$ and this compared to $56.93 \%$ for South in the "all claims" category. Women had higher costs than men $(p<0.0001)$. The age groups with the highest and lowest costs were 55-64 and 18-34. The regions with the highest and lowest costs were North Central and Northeast.

Figure 1 shows the data disaggregated by year. The average MSD medical expenses were higher for females except for 2006. Average costs decreased from 2003 through 2006. South, West and North Central regions experienced similar average costs.

In additional results, we plotted average costs by age groups over these four years. Although the absolute number of medical claims decreased as the age of employees increased, the percent of MSD claims increased with age. Number of employees decreased considerably in $2006(124,900)$ compared to the previous years, 2003-2005 (345,500-444,100). The costs also reduced in the West and North Central regions. This dramatic decrease in number of employees and costs in some regions was likely due simply to a decrease in numbers of retail trade firms participating in the MarketScan databases. There was no such a drop 
Table 1. Distribution of employees and medical costs in retail trade for all years (2003-2006) combined

\begin{tabular}{|c|c|c|c|c|c|c|}
\hline & \multicolumn{2}{|c|}{ Employees with any claim } & \multicolumn{2}{|c|}{ Employees with MSD claims } & \multicolumn{2}{|c|}{ MSD Medical Costs } \\
\hline & $\begin{array}{l}\text { Frequency } \\
(\%)\end{array}$ & $\begin{array}{l}\text { T-statistic or } \\
\chi^{2}(p \text {-value })\end{array}$ & $\begin{array}{l}\text { Frequency } \\
(\%)\end{array}$ & $\begin{array}{l}\text { T-statistic or } \\
\chi^{2}(p \text {-value })\end{array}$ & $\begin{array}{c}\text { Average } \\
\text { Annual Medical } \\
\text { Costs per } \\
\text { Employee }(\$)\end{array}$ & $\begin{array}{l}\text { T-statistic or } \\
\chi^{2}(p \text {-value })\end{array}$ \\
\hline \multicolumn{7}{|l|}{ Gender } \\
\hline Male & $\begin{array}{r}279,593 \\
(36.13)\end{array}$ & $\begin{array}{r}-39.88 \\
(p<0.0001)\end{array}$ & $\begin{array}{l}31,163 \\
(30.55)\end{array}$ & $\begin{array}{r}59,570.66 \\
(p<0.0001)\end{array}$ & $\$ 1,265$ & $\begin{array}{r}-2.67 \\
(p<0.0001)\end{array}$ \\
\hline Female & $\begin{array}{r}494,306 \\
(63.87)\end{array}$ & & $\begin{array}{r}70,860 \\
(69.45)\end{array}$ & & $\$ 1,394$ & \\
\hline \multicolumn{7}{|l|}{ Age Groups } \\
\hline $18-34$ & $\begin{array}{r}296,060 \\
(38.26)\end{array}$ & $\begin{array}{r}78,487.13 \\
(p<0.0001)\end{array}$ & $\begin{array}{l}26,688 \\
(26.16)\end{array}$ & $\begin{array}{r}674.33 \\
(p<0.0001)\end{array}$ & $\$ 815$ & $\begin{array}{r}1,212.20 \\
(p<0.0001)\end{array}$ \\
\hline $35-44$ & $\begin{array}{r}175,856 \\
(22.72)\end{array}$ & & $\begin{array}{l}24,846 \\
(24.35)\end{array}$ & & $\$ 1,297$ & \\
\hline $45-54$ & $\begin{array}{r}170,246 \\
(22.00)\end{array}$ & & $\begin{array}{l}28,004 \\
(27.45)\end{array}$ & & $\$ 1,529$ & \\
\hline $55-64$ & $\begin{array}{r}131,737 \\
(17.02)\end{array}$ & & $\begin{array}{l}22,485 \\
(22.04)\end{array}$ & & $\$ 1,842$ & \\
\hline \multicolumn{7}{|l|}{ Regions $^{1}$} \\
\hline North East & $\begin{array}{r}68,345 \\
(8.83)\end{array}$ & $\begin{array}{l}459,369.48 \\
(p<0.0001)\end{array}$ & $\begin{array}{l}8,150 \\
(7.99)\end{array}$ & $\begin{array}{r}71,735.58 \\
(p<0.0001)\end{array}$ & $\$ 1,032$ & $\begin{array}{r}248.44 \\
(p<0.0001)\end{array}$ \\
\hline North Central & $\begin{array}{r}181,098 \\
(23.40)\end{array}$ & & $\begin{array}{l}22,760 \\
(22.31)\end{array}$ & & $\$ 1,448$ & \\
\hline South & $\begin{array}{r}440,570 \\
(56.93)\end{array}$ & & $\begin{array}{l}61,236 \\
(60.02)\end{array}$ & & $\$ 1,359$ & \\
\hline West & $\begin{array}{l}83,886 \\
(10.84)\end{array}$ & & $\begin{array}{l}9,877 \\
(9.68)\end{array}$ & & $\$ 1,378$ & \\
\hline
\end{tabular}

${ }^{1}$ Border states for the Northeast were Pennsylvania and New Jersey; for the South were Delaware, Maryland, West Virginia, Kentucky, Arkansas, and Oklahoma; for the Midwest were the Dakotas, Nebraska and Kansas; and for the West were Montana, Wyoming, Colorado, New Mexico.

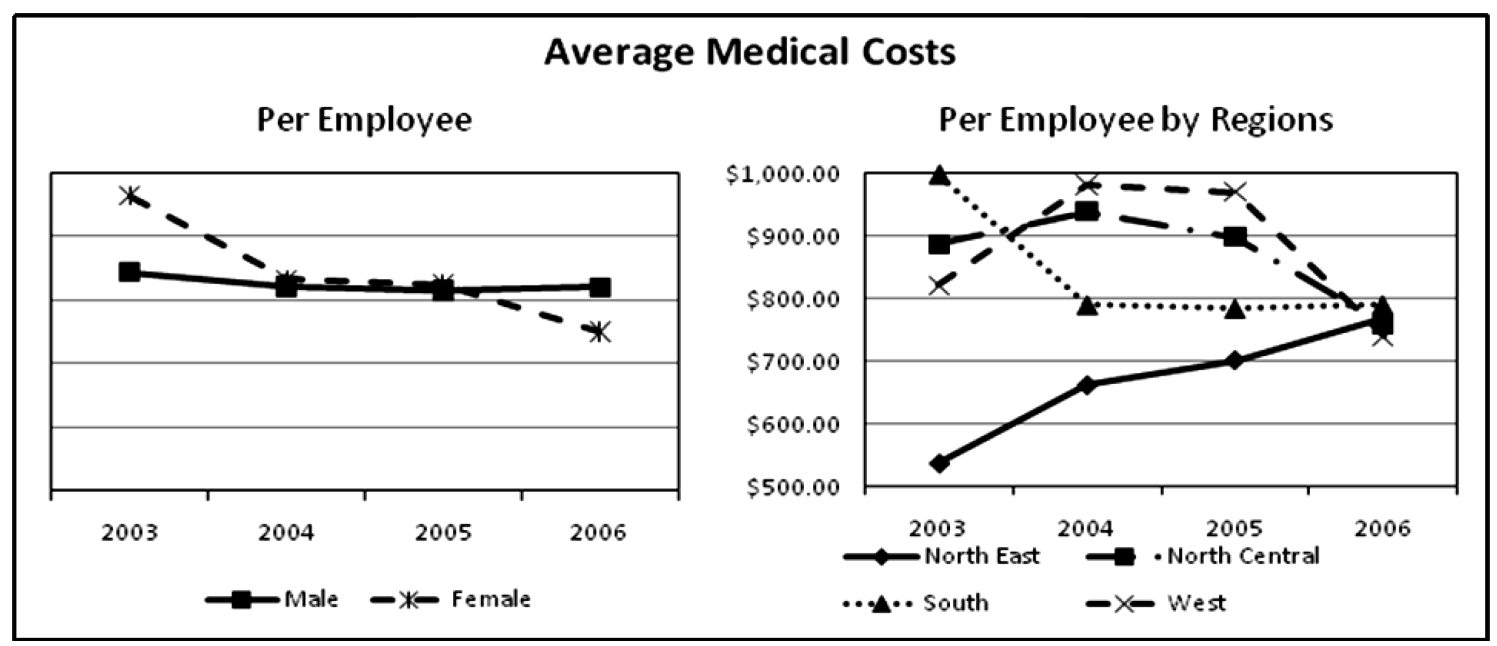

Fig. 1. Average medical costs for MSDs, 2003-2006.

in numbers of employees in the BLS data from 2005 to 2006 $6^{13)}$.

Table 2 presents the average medical costs of MSD related claims by ICD 9 codes. The average costs were highest for lumbar stenosis and lowest for lateral epi- condylitis, tennis elbow. Low back syndrome had the highest number of claims and the highest total cost.

Results from logistic regressions are presented in Table 3. For all MSD claims in the first column of numbers, females were $40 \%$ more likely than males to 
Table 2. Costs by ICD 9 codes for all years (2003-2006) combined, ranked from high to low average cost

\begin{tabular}{lrrr}
\hline ICD 9 Code: Description & Total Cost & N & Average Cost \\
\hline 724.02: Lumbar Stenosis & $\$ 23,000,725$ & 5,271 & $\$ 4,364$ \\
727.61: Complete Rupture of Rotator Cuff & $\$ 2,932,687$ & 1,531 & $\$ 1,916$ \\
724.4: Thoracic or Lumbosacral Neuritis or Radiculitis & $\$ 20,941,141$ & 15,188 & $\$ 1,379$ \\
727.03: Trigger Finger (acquired) & $\$ 3,016,717$ & 2,770 & $\$ 1,089$ \\
727.42: Ganglion of Tendon Sheath & $\$ 989,797$ & 970 & $\$ 1,020$ \\
726.10: Disorders of Bursae and Tendons in Shoulder Region & $\$ 7,939,457$ & 9,132 & $\$ 869$ \\
727.04: Radial Styloid Tenosynovitis & $\$ 1,230,518$ & 1,863 & $\$ 660$ \\
724.2: Low Back Syndrome & $\$ 45,671,696$ & 70,867 & $\$ 644$ \\
727.05: Other Tenosynovitis of Hand and Wrist & $\$ 1,504,368$ & 3,124 & $\$ 481$ \\
724.5: Backache, Unspecified & $\$ 18,544,591$ & 38,896 & $\$ 476$ \\
724.3: Neuritis of Sciatic Nerve & $\$ 4,160,251$ & 9,220 & $\$ 451$ \\
726.31: Medical Epicondylitis & $\$ 262,649$ & 654 & $\$ 401$ \\
726.32: Lateral Epicondylitis, Tennis Elbow & $\$ 1,866,071$ & 4,861 & $\$ 383$ \\
\hline
\end{tabular}

Table 3. Odds ratios for all MSDs, only lumbar stenosis MSD; low back syndrome MSD and non-low back syndrome MSDs

\begin{tabular}{|c|c|c|c|c|c|c|c|c|}
\hline & \multicolumn{2}{|c|}{ All MSDs } & \multicolumn{2}{|c|}{ Lumbar Stenosis } & \multicolumn{2}{|c|}{ Low Back Syndrome } & \multicolumn{2}{|c|}{$\begin{array}{l}\text { Non-Low Back } \\
\text { Syndrome }\end{array}$} \\
\hline & Odds Ratio & $95 \% \mathrm{CI}$ & Odds Ratio & $95 \% \mathrm{CI}$ & Odds Ratio & $95 \% \mathrm{CI}$ & Odds Ratio & $95 \%$ CI \\
\hline \multicolumn{9}{|l|}{ Gender } \\
\hline \multicolumn{9}{|l|}{ Male referent } \\
\hline Female & 1.4 & $1.4-1.41$ & 1.02 & $0.99-1.06$ & 0.94 & $0.94-0.95$ & 1.06 & $1.05-1.07$ \\
\hline \multicolumn{9}{|l|}{ Age Groups } \\
\hline \multicolumn{9}{|l|}{ 18-34 referent } \\
\hline $35-44$ & 2.49 & $2.49-2.49$ & 2.26 & $2.11-2.41$ & 1.11 & $1.10-1.12$ & 0.90 & $0.89-0.91$ \\
\hline $45-54$ & 3.68 & $3.67-3.68$ & 4.31 & $4.06-4.57$ & 0.96 & $0.95-0.97$ & 1.04 & $1.03-1.05$ \\
\hline $55-64$ & 4.04 & $4.03-4.04$ & 7.25 & $6.85-7.69$ & 0.76 & $0.75-0.77$ & 1.31 & $1.30-1.33$ \\
\hline \multicolumn{9}{|l|}{ Regions } \\
\hline Northeast & 0.74 & $0.74-0.74$ & 0.95 & $0.90-1.00$ & 0.87 & $0.86-0.88$ & 1.15 & $1.14-1.17$ \\
\hline North Central & 0.81 & $0.81-0.81$ & 1.12 & $1.09-1.16$ & 0.95 & $0.94-0.95$ & 1.06 & $1.05-1.07$ \\
\hline West & 0.8 & $0.8-0.81$ & 0.96 & $0.91-1.01$ & 1.08 & $1.07-1.09$ & 0.93 & $0.91-0.94$ \\
\hline \multicolumn{9}{|l|}{ South referent } \\
\hline \multicolumn{9}{|l|}{ Years } \\
\hline \multicolumn{9}{|l|}{2003 referent } \\
\hline 2004 & 1.06 & $1.06-1.06$ & 1.03 & $0.99-1.07$ & 1.04 & $1.03-1.05$ & 0.97 & $0.96-0.97$ \\
\hline 2005 & 1.22 & $1.22-1.23$ & 1.06 & $1.02-1.10$ & 1.07 & $1.06-1.08$ & 0.93 & $0.93-0.94$ \\
\hline 2006 & 1.07 & $1.07-1.07$ & 0.98 & $0.92-1.03$ & 1.14 & $1.12-1.15$ & 0.88 & $0.87-0.89$ \\
\hline
\end{tabular}

file an MSD claim. Persons in the 55-64 age group were 4 times more likely and persons in the $45-54$ age group were 3.68 times more likely than those in the 18-34 age group to file a claim. Residents outside the South were roughly 0.78 times as likely (or $22 \%$ less likely) to file claims. The odds increased to 1.06 when comparing 2004 with 2003 and to 1.22 when comparing 2005 with 2003.

Females with lumbar stenosis were $2 \%$ more likely than males to report a lumbar region claim; age groups 45-54 and 55-64 were 4.31 and 7.25 times more likely than age group 18-34 to report claims; and region
North Central was $12 \%$ more likely than Southerners to report claims. For low back syndrome females were $6 \%$ less likely than males to report a claim; age groups 45-54 and 55-64 were 0.96 and 0.76 times as likely as age group 18-34 to report claims; and regions Northeast and North Central were roughly 0.87 and 0.95 times as likely as Southerners to report claims. Females were $6 \%$ more likely than males to file non-low back syndrome claims. Age groups 45-54 and 55-64 were 4\% and $31 \%$ more likely than the age group 18-34 to report non-low back syndrome claims; Northeast and North Central were $15 \%$ and $6 \%$ more likely than Southerners 
to report non-low back syndrome claims. In separate logistic regressions run for the different ICD 9 codes, results suggested that for the top three MSD related ICD 9 codes females were more likely than males to report claims: for radial styloid tenosynovitis (727.04) females were 3.32 times more likely; or for trigger finger acquired (727.03), females were 2.29 times; and for ganglion of tendon sheath (727.42), 1.55 times more likely.

This study found that about $3.5 \%$ of all medical claims in retail trade were attributed to MSDs. Claims related to low back syndrome resulted in the highest frequency and claims related to lumbar regions were the most expensive per-claim. The odds of filing an MSD claim did not vary significantly over 2003-2006 and varied only slightly across regions.

The results also indicate that the odds of filing a medical claim for MSDs was higher for women than men. This can be attributed to more MSDs in women due to child care, more severe MSDs, more visits to doctors' offices by women than men. The latter can raise the numbers of claims as well as the average and total costs ${ }^{14)}$. The medical claims increased with age, as expected. This can raise the incidence, prevalence and severity of diseases resulting in older workers with more MSDs and higher total costs and average costs. The outcomes also show claims incidence is higher for employees residing in the South. This can be due to the fact that the southern region had more workers employed in the retail trade sector during this period according to the BLS ${ }^{13)}$. With some exceptions, similar findings were observed for odds of filing for lumbar region and low back syndrome. One such exception was that the odds of filing claims for lumbar regions increased with age but decreased with age for low back syndrome.

These findings regarding increasing age, costs, and odds of filing claims are consistent with those from Peele, Xu, and Colombi (2005) ${ }^{5)}$ who found similar differences in terms of lost work time per employee in a sample of exclusively occupational MSDs. Our findings can also be compared to claims data from 37 states combined in Shuford et al (2009) ${ }^{15)}$. Although the Shuford et al (2009) data covered only workers compensation claims and were not limited to MSDs, they found lumbar stenosis, lumbar disc and lumbago among the top seven claim categories. Similarly, we found that the lumbar stenosis, low back syndrome, and unspecified backache were ranked highest for claims frequency. One of the reasons for lumbar stenosis to be the most expensive category can be attributed to the surgeries as one of the treatment procedures.

Our findings can be used to estimate the medical costs of MSDs in the retail trade sector. According to BLS data about $11 \%$ of workers were employed in the retail trade sector during the years 2003 through $2006^{16)}$ and our results suggest that roughly $13 \%$ of retail trade employees filed for MSD related claims. Finally, medical workers compensation costs were $\$ 27.2$ billion in 20077). We therefore estimated that $\$ 27.2 \times 13 \% \times 11 \%=\$ 0.389$ billion; retail MSD generated about $\$ 389$ million of medical costs in workers compensation claims in 2007.

An important limitation of this study is that the MSD claims could not be distinguished as occupational or non-occupational. However, as noted above, this lack of distinction may be an advantage since workers compensation (occupational) medical prices may be inflated ${ }^{9)}$ and more than half of job-related MSDs may not be reported to workers compensation (as occupational) ${ }^{10}$. Another limitation is that the population of this study belongs to large corporations; hence the results do not portray the true national picture. It is likely that large corporations provide better health care coverage than smaller firms which might raise the frequency of doctors' office visits and therefore increase the numbers of claims and average costs and total costs. If this study can be extended to the national level, the probability of obtaining lower average costs, total costs and fewer claims is high. A drop in claims and costs may indicate fewer cases of reported MSDs. However, the drop would be misleading since people with no health insurance or limited coverage rarely show up in the claims and costs. Still, these data can complement other data or be used as benchmarks against them.

In conclusion, age and gender were strong predictors of medical claim frequency and costs from MSDs in the US retail sector. These findings suggest that future research should focus on the overall burden of MSDs including lost work time and costs to society. In addition, differences in lost work time due to longer recovery periods among older employees and the portion that might be attributed to the differences in the nature and/or severity of MSDs between older and younger employees needs to be explored.

\section{Acknowledgements}

JP Leigh acknowledges partial support from the National Institute for Occupational Safety and Health (OH008248-01).

\section{References}

1) National Institute for Occupational Safety and Health (NIOSH) Worker Health Chartbook (2004) 
Web site. http://www.cdc.gov/niosh/docs/2004-146/ pdfs/2004-146.pdf. Accessed May 25, 2010.

2) Bureau of Labor Statistics (2009) Number, percent, and incidence rate of nonfatal occupational injuries and illnesses involving days away from work by selected worker and case characteristics and musculoskeletal disorders: All United States, private industry, 2007. Web site. U.S. Department of Labor. (http://www.bls.gov/iif/oshwc/osh/case/ostb1941.pdf). Accessed June 12, 2010.

3) Hashemi L, Webster BS, Clancy EA, Courtney TK (1998) Length of Disability and cost of work-related musculoskeletal disorders of the upper extremity. J Occup Environ Med 40, 261-9.

4) Crook J, Modolfsky H (1994) The probability of recovery and return to work from work disability as a function of time. Qual Life Res 3 (Suppl 1), S97-S109.

5) Peele PB, Xu Y, Colombi A (2005) Medical care and lost work day costs in musculoskeletal disorders: older versus younger workers. International Congress Series 1280, 214-8.

6) Fisher ES, Bynum JP, Skinner JS (2009) Slowing the growth of health care costs -lessons from regional variation. N Engl J Med 360, 849-52.

7) Sengupta I, Reno V, Burton JF (2009) Workers' compensation: benefits, coverage, and costs. National Academy of Social Insurance; 2007, Washington DC.

8) Punnett L (2000) Commentary on the scientific basis of the proposed occupational safety and health administration ergonomics program standard. J Occup
Environ Med 42, 970-81.

9) Baker LC, Krueger AB (1995) Medical costs in workers' compensation insurance. J Health Econ 14, $531-49$.

10) Morse T, Dillon C, Kenta-Bibi E, Weber J, Diva U, Warren N, Grey M (2005) Trends in work-related musculoskeletal disorder reports by year, type, and industrial sector: a capture-recapture analysis. Am J Ind Med 48, 40-9.

11) Hansen LG, Chang S (2010) Health Research Data for the Real World: The MarketScan Databases. Adamson DM, White paper (2010). http://thomsonreuters. com/products_services/healthcare/healthcare_products/ pharmaceuticals/mktscan_res_db/. Accessed December $16,2010$.

12) Zhang J, Yu KF (1998) A method of correcting the odds ratio in cohort studies of common outcomes. JAMA 280, 1690-1.

13) Bureau of Labor Statistics, Overview of Statistics on Employment. http://www.bls.gov/bls/employment. $\mathrm{htm}$ and http://www.bls.gov/news.release/history/ laus_01232007.txt. Accessed June 15, 2010.

14) Sindelar JL (1982) Differential use of medical care by sex. J Political Economy 90, 1003-19.

15) Shuford H, Restrepo T, Beaven N, Leigh JP (2009) Trends in components of medical spending within workers compensation: results from 37 states combined. J Occup Environ Med 51, 232-8.

16) US Department of Labor, BLS News: Washington DC, 20212, 2008. http://www.bls.gov/news.release/archives/ empsit_020120. Accessed August 10, 2010. 